\title{
Tricalcium phosphate and hydroxyapatite treatment for benign cavitary bone lesions: A prospective clinical trial
}

\author{
ŞERBAN DRAGOSLOVEANU ${ }^{1,3}$, CHRISTIANA D.M. DRAGOSLOVEANU ${ }^{2}$, HORIA T. STANCA ${ }^{2}$, \\ DRAGOŞ C. COTOR ${ }^{3}$, ADRIAN C. ANDREI ${ }^{3}$, CĂLIN I. DRAGOSLOVEANU ${ }^{3}$ and CRISTIAN I. STOICA ${ }^{1,3}$ \\ Departments of ${ }^{1}$ Orthopedics, and ${ }^{2}$ Ophthalmology, 'Carol Davila' University of Medicine and Pharmacy, \\ 050474 Bucharest; ${ }^{3}$ Department of Orthopedic Surgery, 'Foişor' Orthopedics-Traumatology \\ and Osteoarticular TB Hospital, 030167 Bucharest, Romania
}

Received September 4, 2020; Accepted October 5, 2020

DOI: $10.3892 / \mathrm{etm} .2020 .9345$

\begin{abstract}
Benign bone tumors are surgically treated by curettage and by filling the defect using bone grafts or bone substitutes, such as hydroxyapatite crystals and tricalcium phosphate. The tricalcium phosphate mixed with hydroxyapatite, although fragile, is a good alternative with good integration. Fifteen patients with benign bone lesions were randomized in two groups surgically treated by curettage and filling of the bone defect using allograft (7 cases) or a mixture of $35 \%$ tricalcium phosphate, with $60-85 \%$ pore volume, and $65 \%$ hydroxyapatite ( 8 cases). After the surgery, all patients were followed up every 3 weeks until 6 months, and then at 2 months interval until one year for the clinical and radiological assessment. The average age was 35.4 years (from 18 to 54 ) for the allograft group and 41 years (from 22 to 58) for the patients treated with bone substitute. Eight patients were male and seven female, with relatively equal distribution between both groups. The average bone defect was relatively equal: $14 \mathrm{cc}(4-25 \mathrm{cc})$ for the allograft group and $15.1 \mathrm{cc}(4-33 \mathrm{cc})$ for the ceramic group $(\mathrm{P}>0.1)$. During the follow-up, all the lesions gradually disappeared after 12 months, with a time of healing of 18.8 weeks (15-24 weeks) for the allograft group and 20.37 weeks (15-28) for the bone substitute group. There were no significant differences regarding the clinical status and the radiological assessment after 12 months. No patient required extra pain medication after 2 weeks. No complications have been recorded. The surgical treatment of small and medium sized lytic benign tumors has good results with both types of graft that were studied. Using tricalcium phosphate mixed with hydroxyapatite as bone substitute represents a good and
\end{abstract}

Correspondence to: Dr Christiana D.M. Dragosloveanu, Department of Ophthalmology, 'Carol Davila' University of Medicine and Pharmacy, Bulevardul Eroii Sanitari 8, 050474 Bucharest, Romania

E-mail: christianacelea@gmail.com

Key words: benign, bone cyst, bone substitute, prospective, humans, ceramic, tricalcium phosphate low cost alternative, but it is a relatively fragile material with a slower time to integrate compared to the allograft.

\section{Introduction}

The lytic benign bone tumors are usually surgically treated using curettage and filling the defect using bone graft (autograft or allograft) or bone substitutes, such as hydroxyapatite crystals and tricalcium phosphate (1-4). The location and the size of the bone defect are critical elements that determine the bone regeneration (5). The autologous bone graft is a very effective method, usually harvested from the iliac crest. The major flaw of this resource is the very limited bone that can be harvested and requires an additional surgical intervention that usually creates a local postoperative chronic pain $(6,7)$. The allografts need to be preserved in special conditions, that may not be available in some clinical centers and, besides the methods of sterilization, some studies show an increased rate of infections, but also a decreased integration $(8,9)$. For this reason, various alternatives had been studied, such as xenografts or bone substitutes. Unfortunately, the xenograft has issues because of a slower integration and a greater risk of allergic reactions and infections (7). The bone substitutes are biomaterials that are either of human, animal, vegetal or synthetic origin, especially prepared for filling bone defects, enhancing bone structure or bone replacement (10-12). The tricalcium phosphate combined with hydroxyapatite, used as scaffold, is a good composition with a similar structure to the bone, with a good integration. They are generally used in dental and maxillofacial surgeries. The major advantage of this composite is that the tricalcium phosphate is resorbed, leaving a new formed bone tissue (8). One of the disadvantages is the fragility of the calcium phosphate, thus, it is not indicated in large bone defects. The aim of the present study is to compare the efficiency of bone substitute formed of 35\% tricalcium phosphate and 65\% hydroxyapatite with the simple bone grafts in the surgical treatment of bone lesions.

\section{Materials and methods}

Fifteen patients with benign lesions in different localizations were included in our prospective randomized comparative study at 'Foisor' Orthopedics Hospital, Bucharest, Romania, 
between 2016 and 2019. They underwent a curettage and filling of the bone defect using allograft or a biphasic mixture made of $35 \%$ tricalcium phosphate, with $60-85 \%$ pore volume and $65 \%$ hydroxyapatite.

Any patient with benign small or medium sized bone lytic lesions (Fig. 1), unicameral bone cyst (Fig. 2), non-ossifying fibroma or giant cell tumor (Fig. 3) localized in a non-structural area were included. The exclusion criteria were patients suspect of malignant bone tumors, local infections, pre-existing metabolic calcium disorders or patients with large lesions that required supplementary internal fixation.

All the patients were under general anesthesia and the surgical procedures were guided under fluoroscopy. The surgical approach was different depending on the localization of the bone lesion. After the dissection and the periosteal incision, the wall of the cyst was opened and the fluid content aspirated. The cavity wall or the tissue within the lesion was curetted and cauterized and, after that, the cavity was filled with morselized allograft in 7 cases or a composite ceramic granular material in 8 cases. In the end, the periosteum was sutured over the filling. The specimens from the bone were sent for pathological examination. After the surgery, no weight bearing was recommended for patients with bone lesions in the lower limb for 6 weeks. For the upper limb, a 6 weeks sling immobilization was recommended.

The patient age, sex, bone size and localization were recorded preoperatively using the X-ray and CT scan imaging and Cedara I-View 6.3.3 (Cedara Software Corp.). After the surgery, all patients were followed up every 3 weeks until 6 months, and then every 2 months until 1 year for the clinical and radiological assessment. We used the modified Neer grading system to assess the amount of bone healing after adding the bone graft $(13,14)$ (Table I). All the data was assessed using IBM SPSS Statistics 25.0.0 for Microsoft Windows (IBM Corporation) and the statistical significance was set at $\mathrm{P}<0.05$. The baseline characteristics were assessed using the Independent samples t-test. The study was approved by the Ethics Committee of 'Foişor' Orthopedics-Traumatology and Osteoarticular TB Hospital (Bucharest, Romania). All patients provided a signed informed consent.

\section{Results}

Fifteen patients were followed for 12 months in our clinic. The average age was 35.4 years (from 18 to 54 ) for the allograft group and 41 years (from 22 to 58) for the patients treated with bone substitute. Eight patients were male and seven female with relatively equal distribution between both groups (Table II). The localizations of the lesions are presented in Table III. The average bone defect was relatively equal $14 \mathrm{cc}(4-25 \mathrm{cc})$ for the allograft group and $15.1 \mathrm{cc}(4-33 \mathrm{cc})$ for the ceramic group $(\mathrm{P}>0.1)$.

During the follow-up, all the lesions gradually disappeared after 12 months, with a time of healing of 18.8 weeks (15-24 weeks) for the allograft group and 20.37 weeks (15-28 weeks) for the bone substitute group. The amount of healing was almost similar in both groups. In the allograft group, 5 patients presented a substantial healing (Neer 1) and 2 patients were partially healed (Neer 2). In the second group, only 3 patients presented a partial healing (Neer 2) (Table IV). None of the patients showed any persistent cysts or lack of response to the surgical treatment. After 12 months, the

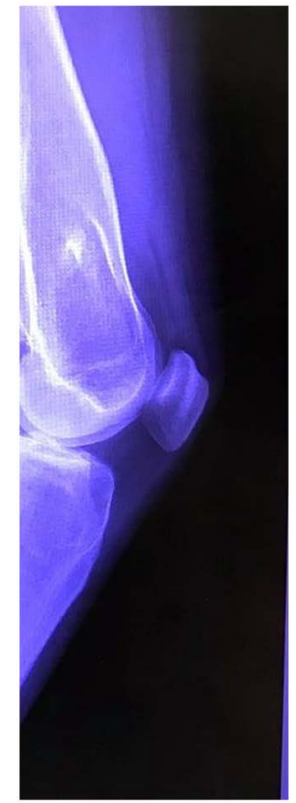

Figure 1. A lytic bone lesion found on the left distal femur.

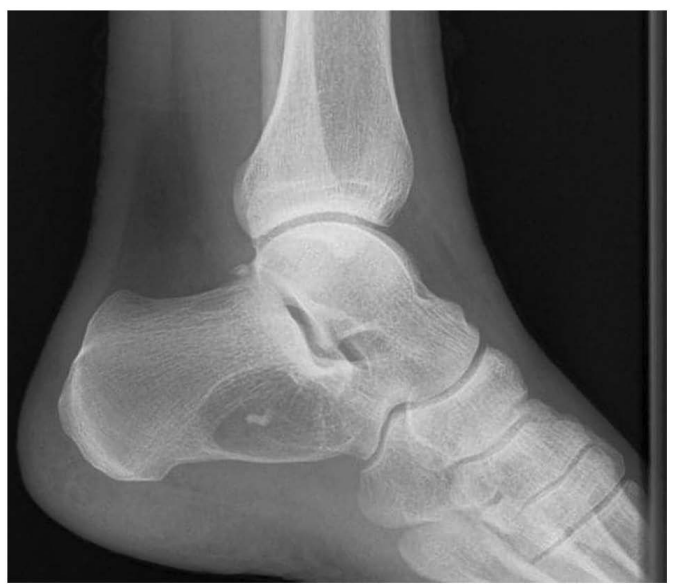

Figure 2. A unicameral bone cyst found on the left calcaneus.

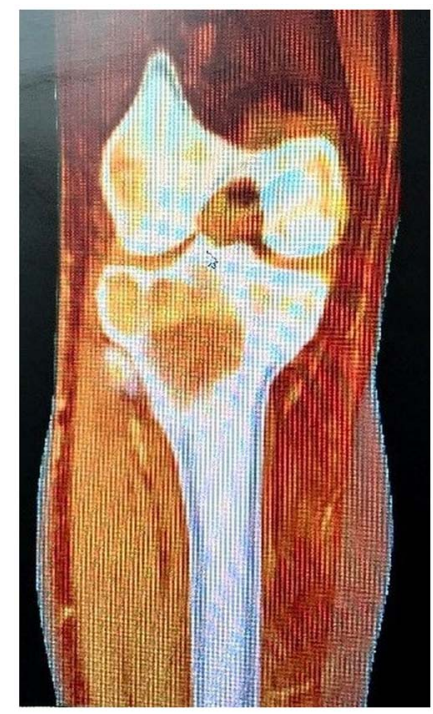

Figure 3. Giant cell tumor localized in the proximal tibia of a male patient aged 55 years. 
Table I. The modified Neer grading system.

\begin{tabular}{lll}
\hline Score & Classification & \multicolumn{1}{c}{ Description } \\
\hline 1 & Healed & The lesion is completely filled with new formed bone. \\
2 & Partially healed & $\begin{array}{l}\text { Radiolucent areas smaller than } 50 \% \text { of the diameter of the bone and no increase of size or lucencies } \\
\text { over time. } \\
\text { Radiolucent areas bigger than } 50 \% \text { of the diameter of the bone that may increase over time and may } \\
\text { need to continue the restrictions or repeat the surgical procedure. }\end{array}$ \\
& Persistent cyst & No bony healing evidence. Repetition of the surgical treatment is required.
\end{tabular}

Table II. General data regarding the age, sex and the average size of the bone lesions.

\begin{tabular}{lccc}
\hline Variable & Allograft & Ceramic & P-value \\
\hline Age & 35.4 & 41 & $\mathrm{n} / \mathrm{a}$ \\
Sex (M/F) & $4 / 3$ & $4 / 4$ & $\mathrm{n} / \mathrm{a}$ \\
Bone defect size & $14 \mathrm{cc}$ & $15.1 \mathrm{cc}$ & $>0.1$ \\
\hline
\end{tabular}

Table III. Localizations of bone lesions.

\begin{tabular}{lcc}
\hline Localization & Allograft & Ceramic \\
\hline Clavicle & 1 & - \\
Proximal humerus & 1 & 2 \\
Humeral diaphysis & 3 & 1 \\
Distal femur & - & 1 \\
Proximal tibia & 1 & 2 \\
Calcaneus & 1 & 2 \\
\hline
\end{tabular}

Table IV. Treatment outcome.

\begin{tabular}{lcc}
\hline Neer & Allograft group & Ceramic graft \\
\hline Type 1 & 5 & 5 \\
Type 2 & 2 & 3 \\
Type 3 & - & - \\
Type 4 & - & - \\
\hline
\end{tabular}

CT scan confirmed the integration of the graft. We did not encounter any significant differences regarding the functional or clinical status and no patient required extra pain medication after 2 weeks. There were no local infections or bone fractures recorded. We did not find any correlation between the age, sex, location of the lesion and the outcome of the treatment $(\mathrm{P}>0.1)$.

\section{Discussion}

The bone defects derived from bone tumors remain a challenging surgical problem from economic and social standpoint (15). The autograft is the golden standard; however, factors such as the longer surgery time, morbidity associated to the donor site and the limited bone that is available make the allograft, if available, a good alternative. We did not record any kind of postoperative complications regarding the allograft technique, but in literature, the following are mentioned: immune-rejections, bacterial infections and viral transmission as the limitations of this procedure $(16,17)$. Tricalcium phosphate could be a good bone substitute because they have a low cost; it could be an alternative for patients who do not accept graft transplant for ethical reasons and it offers a biological response similar to natural bone. The chemical composition, porosity, and mechanical properties are the most important elements when a bone substitute is developed (18). In the present study, we had the same results regarding the grade of integration of the graft compared with the group treated with allograft. It seems that this kind of bone substitute enables, by microporosity itself, the bone fluids and tissues to impregnate the implant that will promote the ingrowth of an early bone (19). Nonetheless, the bone healing was slower for the group treated with tricalcium phosphate. It is mentioned in literature that this type of graft needs over 9 to 12 months to achieve full integration and transformation into bone $(19,20)$. In addition, the proportion of tricalcium phosphate and hydroxyapatite influences the time for the bone remodeling. If the hydroxyapatite has a bigger proportion than the phosphate, the bone requires a longer time to remodel (21). Literature also mentions that grafts made mainly from calcium phosphate may cause adverse soft tissue reactions and they have the tendency to dissolve very quickly $(22,23)$.

One of the major disadvantages of the tricalcium phosphate/hydroxyapatite is the fragile structure and the low mechanical properties, which is an important detail to be taken into account in cases where the bone is exposed to high mechanical stress (24). That is why it is not recommended in large bone defects without additional internal fixation and graft augmentation. The age and the sex of the patients did not influence the outcome of the treatment.

One of the main limitations of this study is the small number of patients included and a short follow up. Although both types of treatment demonstrated good results, a larger number of cases and a longer time of follow up may be necessary to fully assess the rate of integration and the complications. The size of the lesion may influence the outcome, which may require a further radiological and histological assessment.

In conclusion, the surgical treatment of small and medium sized lytic benign tumors has good results with both type of grafts that have been studied. Using tricalcium phosphate 
mixed with hydroxyapatite as bone substitute is a good and low cost alternative, but it is a relatively fragile material with a slower time to integrate compared to the allograft.

\section{Acknowledgements}

Professional editing, linguistic and technical assistance was performed by Irina Radu, Individual Service Provider, certified translator in Medicine and Pharmacy (certificate credentials: Series E no. 0048).

\section{Funding}

No funding was received.

\section{Availability of data and materials}

All data generated or analyzed during this study are included in this published article.

\section{Authors' contributions}

SD planned the clinical study, performed the surgical procedures, contributed to the conception and design of the study, and the acquisition, analysis and interpretation of the data. CDMD contributed to the conception and design of the study, analysis of data, the drafting of the manuscript and its critical revision for important intellectual content. DCC contributed to the analysis and interpretation of the data and the critical revision for important intellectual content. ACA contributed to the acquisition, analysis and interpretation of the data and the critical revision for important intellectual content. CID and HTS contributed to the conception and design of the study and the critical revision of the manuscript for important intellectual content. CIS contributed to the conception and design of the study, the interpretation of the data and the critical revision of the manuscript for important intellectual content. All authors read and approved the final version of the manuscript and agreed to be accountable for all aspects of the study.

\section{Ethics approval and consent to participate}

The study was approved by the Ethics Committee of 'Foişor' Orthopaedics-Traumatology and Osteoarticular TB Hospital (Bucharest, Romania). All patients provided a signed informed consent.

\section{Patient consent for publication}

Not applicable.

\section{Competing interests}

The authors declare that they have no competing interests.

\section{References}

1. Jäger M, Herten M, Fochtmann U, Fischer J, Hernigou P, Zilkens C, Hendrich C and Krauspe R: Bridging the gap: Bone marrow aspiration concentrate reduces autologous bone grafting in osseous defects. J Orthop Res 29: 173-180, 2011.
2. Damron TA: Use of 3D beta-tricalcium phosphate (Vitoss) scaffolds in repairing bone defects. Nanomedicine (Lond) 2: 763-775, 2007.

3. Delloye C, Cnochaert N and Corbu O: Bone substitutes in 2003: An overview. Acta Orthop Belg 69: 1-8, 2003.

4. Larsson S: Calcium phosphates: What is the evidence? J Orthop Trauma 24 (Suppl 1): S41-S45, 2010.

5. Hirn M, de Silva U, Sidharthan S, Grimer RJ, Abudu A, Tillman RM and Carter SR: Bone defects following curettage do not necessarily need augmentation: A retrospective study of 146 patients. Acta Orthop 80: 4-8, 2009.

6. Banwart JC, Asher MA and Hassanein RS: Iliac crest bone graft harvest donor site morbidity. A statistical evaluation. Spine (Phila $\mathrm{Pa}$ 1976) 20: 1055-1060, 1995.

7. Fernyhough JC, Schimandle JJ, Weigel MC, Edwards CC and Levine AM: Chronic donor-site pain complicating graft harvesting from the posterior iliac crest for spinal fusion. Spine (Phila Pa 1976) 17: 1474-1480, 1992.

8. Daculsi G, LeGeros RZ, Nery E, Lynch K and Kerebel B: Transformation of biphasic calcium phosphate ceramics in vivo: Ultrastructural and physicochemical characterisation. J Biomed Mater Res 23: 883-894, 1989.

9. Khan Y, Yaszemski MJ, Mikos AG and Laurencin CT: Tissue engineering of bone: Material and matrix considerations. J Bone Joint Surg Am 90 (Suppl 1): S36-S42, 2008.

10. Daculsi G, Weiss P, Bouler JM, Gauthier O, Millot F and Aguado E: Biphasic calcium phosphate/hydrosoluble polymer composites: A new concept for bone and dental substitution biomaterials. Bone 25 (2 Suppl): 59S-61S, 1999.

11. Van Blitterswijk CA, Grote JJ, Kuijpers W, Daems WT and De Grout K: Macrospore tissue ingrowths: A quantitative and qualitative study on hydroxyapatite ceramics. Biomaterials 7: 137-143, 1986.

12. Daculsi G and Passuti N: Effect of the macro porosity for osseous substitution of calcium phosphate ceramics. Biomaterials 11: 86-87, 1990.

13. Neer CS II, Francis KC, Marcove RC, Terz J and Carbonare P: Treatment of unicameral bone cysts: A follow up study of one hundred seventy-five cases. J Bone Joint Surg Am 48: 731-745, 1966.

14. Chapman MW, Bucholz R and Cornell C: Treatment of acute fractures with collagen-calcium-phosphate graft material. A randomized clinical trial. J Bone Joint Surg Am 79: 495-502, 1997.

15. Stanovici J, Le Nail LR, Brennanetal MA, Vidal L, Trichet V, Rosset $\mathrm{P}$ and Layrolle P: Bone regeneration strategies with bone marrow stromal cells in orthopaedic surgery. Curr Res Transl Med 64: 83-90, 2016.

16. Calori GM, Mazza E, Colombo M and Ripamonti C: The use of bone-graft substitutes in large bone defects: Any specific needs? Injury 42 (Suppl 2): S56-S63, 2011.

17. Dumic-Cule I, Pecina M, Jelic M, Jankolija M, Popek I, Grgurevic L and Vukicevic S: Biological aspects of segmental bone defects management. Int Orthop 39: 1005-1011, 2015.

18. Bohner M: Physical and chemical aspects of calcium phosphates used in spinal surgery. Eur Spine J 10 (Suppl 2): S114-S121, 2001.

19. Nilsson M, Zheng MH and Tagil M: The composite of hydroxyapatite and calcium sulfate: A review of preclinical evaluation and clinical applications. Expert Rev Med Devices 10: 675-684, 2013.

20. Hatten HP Jr and Voor MJ: Bone healing using a bi-phasic ceramic bone substitute demonstrated in human vertebroplasty and with histology in a rabbit cancellous bone defect model. Interv Neuroradiol 18: 105-113, 2012.

21. Schindler OS, Cannon SR, Briggs TW and Blunn GW: Composite ceramic bone graft substitute in the treatment of locally aggressive benign bone tumours. J Orthop Surg (Hong Kong) 16: 66-74, 2008.

22. Petruskevicius J, Nielsen S, Kaalund S, Knudsen PR and Overgaard S: No effect of Osteoset, a bone graft substitute, on bone healing in humans: A prospective randomized double-blind study. Acta Orthop Scand 73: 575-578, 2002.

23. Welkerling H, Raith J, Kastner N, Marschall C and Windhager R: Painful soft-tissue reaction to injectable Norian SRS calcium phosphate cement after curettage of enchondromas. J Bone Joint Surg Br 85: 238-239, 2003.

24. Golberg VM and Stevenson S: Natural history of autografts and allografts. Clin Orthop Relat Res: 7-16, 1987. 